Thorax (1951), 6, 230.

\title{
THORACOPLASTY CONCOMITANT WITH RESECTION FOR PULMONARY TUBERCULOSIS
}

\author{
BY \\ J. K. B. WADDINGTON \\ From the Thoracic Surgical Unit, Aintree Hospital, Liverpool
}

(RECEIVED FOR PUBLICATION APRIL 17, 1951)

Resection of the lung has been accepted as a satisfactory method of treating certain types of pulmonary tuberculosis. In assessing large numbers of cases for resection very few are found to be entirely free from healed or quiescent lesions in the parts of the lung which will remain after excision. The space left after the resection of a lobe or lung gives the surgeon anxiety, since it can only be filled by adjustment of the remaining lung tissue and by deviation of the mediastinum to the operated side. This adjustment causes distension of the lung, which, in addition to setting up stresses on quiescent lesions, reduces its efficiency as an aerating organ.

In this paper 18 cases of pneumonectomy and 20 of upper lobectomy, in which a modified thoracoplasty was performed concomitantly with the resection in an effort to prevent distension, are reviewed. The cases are from a series of 62 lobes and 20 lungs which were subjected to resection in the Aintree Thoracic Unit between May and December, 1950. In some the decision to carry out thoracoplasty was made before operation, but in the others it was made during the operation.

Although difficult to prove conclusively, it is suspected that stretching a quiescent tuberculous lesion may cause reactivation, possibly by breaking down the fibrous tissue boundary laid down during healing. This has been seen where an artificial pneumothorax has been abandoned either deliberately or inadvertently and a previously controlled lesion has become active again. Moreover, cases have been seen where, after a resection has been done, an ipsilateral or contralateral lesion which has been radiologically stable for 12 months has reactivated soon after the operation.

In addition to the risk of activation, the physiological effects of removing lung tissue have to be considered. It is still a matter of controversy what degree of compensation can occur in the remaining lung after lobectomy or pneumonectomy. Longacre and Johansmann (1940), Cournand and Berry (1942), and Lester, Cournand, and Riley (1942) studied children and young animals after pneumonectomy and decided that the operation had little detrimental effect in the young, but, when carried out in older age groups, emphysema developed which led to respiratory embarrassment.

Reinhoff, Reichert, and Heuer (1935) and Reinhoff (1949) did not believe that emphysema occurred after pneumonectomy; they thought that "compensatory 
dilatation" occurred. They therefore did not consider it necessary to perform thoracoplasty or employ any other method of preventing lung distension after resection.

Work by Burnett, Long, Norris, Rosemond, and Wester (1949) on patients subjected to pneumonectomy for a variety of diseases, and on whom they performed pre- and post-operative bronchospirometry, suggested that most patients compensated for the removal of their lung whilst at rest, but that exercise produced dyspnoea and distress, especially in the older patients or those with fibrosis or emphysema of the remaining lung.

These findings are relevant to resection of tuberculous lungs in so far as a patient may be cured of his tuberculosis in early years but may become a respiratory cripple in later life if steps are not taken to prevent over-distension.

\section{Methods of Preventing Over-Distension}

It is the custom in this unit to induce a pneumoperitoneum before resection and to perform, usually at the time of resection, a temporary phrenic interruption in lobectomies and a permanent interruption in pneumonectomies. The resulting ascent of the diaphragm is a satisfactory means of filling the space after lower lobectomy. But after upper lobectomy, even with full mobilization of the lower lobe, the space may not be filled and hyperdistension of the apex of the lower lobe or middle lobe may occur. After pneumonectomy the hemithorax may be reduced in volume but is never completely filled, except where a post-resection effusion collects.

Some surgeons have used plastic prostheses to fill post-pneumonectomy hemithoraces, and Brantigan and Rigdon (1950) have published a series of 23 cases in which they filled the hemithorax with leucite balls inserted some weeks after resection. They made a point that they "wait some weeks lest the balls might be harmful in the post-operative period." Despite this they had two empyemata, one tuberculous and the other pyogenic in origin.

Temple (1951) has tried polythene packs inserted extrapleurally after pneumonectomy to push the lateral chest wall against the mediastinum. He has now abandoned this method and prefers to carry out a thoracoplasty.

Thoracoplasty is the most widely used and the safest method of reducing postresection spaces and of maintaining or restoring the mediastinum to a central position.

Price Thomas (1950) performed a routine thoracoplasty 10 days or so after pneumonectomy for tuberculosis, but Holmes Sellors (1950) discriminated between those cases having radiologically healthy contralateral lungs and those showing signs of tuberculous lesions ; in the latter he performed thoracoplasty two or more weeks after the pneumonectomy.

Overholt and Langer (1949) performed an anterior-stage thoracoplasty six weeks after pneumonectomy and completed the thoracoplasty by a posterior stage 10 days later. They have also extended the method to cases of upper lobectomy and now remove short segments from the posterior ends of the second to fourth ribs six weeks after resection. 
The time interval between resection and corrective measures is of importance if over-distension is to be prevented. Distension must begin immediately a lung or lobe is removed and with it the factors initiating reactivation of doubtfully healed or quiescent lesions. Therefore, it would appear that the ideal time to perform corrective thoracoplasty, provided it is not detrimental to the patient, is at the time of the resection.

A similar view was expressed by Iverson and Skinner (1950), who published a series of 10 patients whom they subjected to a modified thoracoplasty immediately after removal of the lung for various diseases. In this unit we adopted a similar procedure with pneumonectomy for tuberculosis, and extended it to upper lobectomies in selected cases. A factor which also influenced its use in lobectomy was that, if the lower lobe was allowed to over-distend for several weeks, subsequent thoracoplasty compressed only the apex of the lobe and left the basal segments distended.

Since the method was adopted papers by Himmelstein, Berry, and Read (1950) and by Jones and Robinson (1950) have shown their interest in corrective thoracoplasties after upper lobectomy. The former believed that thoracoplasty should be done concomitantly or even before resection; the latter gave figures suggesting that early complications were about the same whether the lobectomy cases were protected by thoracoplasty or not. On the other hand, late complications were less when thoracoplasty was done.

\section{INDICATIONS FOR ThORACOPLASTY CONCOMITANT WITH RESECTIONS}

Pneumonectomy.-In most cases where pneumonectomy has been carried out immediate thoracoplasty is indicated, especially if there is or has been evidence of tuberculous lesions in the contralateral lung.

Upper Lobectomy.-Where a pneumoperitoneum is contraindicated or impracticable by reason of inflammatory changes above or below the diaphragm, or where there has been radiological evidence of tuberculosis in the contralateral lung, concomitant thoracoplasty should be done. Other indications are when palpation reveals quiescent lesions in the ipsilateral lung, too few or too small to warrant more extensive resection; or when the remaining lobe or lobes, though free from palpable disease, are too small to fill the hemithorax without over-distension. The latter condition is especially significant in older patients. Finally when a large apical lower segment on the left side or the right middle lobe is removed with the upper lobe concomitant thoracoplasty is indicated.

\section{TECHNIQUE}

Since one of the advantages of resection for tuberculosis is the absence of deformity, we aim to remove sufficient lengths of bone from the posterior ends of the ribs to produce a good "falling in " of the chest wall, but leave the first rib intact, only relaxing the extrapleural tissues and periosteum from its under-surface. If thoracoplasty is indicated the standard incision for resection is prolonged higher than normal, and the trapezius and rhomboid muscles also are divided higher up. On the other hand, if the decision to perform thoracoplasty is only made during the operation it is usually possible to resect as high as the second rib without any modification of the cutaneous or muscular 
approach. Standard dissection technique is used in the resection and, if the anaesthetist considers the patient's condition satisfactory, thoracoplasty is carried out before the chest is closed. In the period under review, only one pneumonectomy and one lobectomy were considered unfit for the added stress of thoracoplasty.

Resecting the fifth rib for lobectomy and usually the sixth rib for pneumonectomy, the thoracoplasty is completed by removing graded lengths from the second to the fourth or fifth ribs respectively, usually $1 \frac{1}{2}$ in. from the second to $3 \frac{1}{2}$ in. from the fifth. The transverse processes are not shortened nor are the intercostal bundles divided. With this extent of rib resection the scapula remains in its normal position and only falls in after pneumonectomy if the scapula is shorter than average. Cosmetic considerations are sacrificed in pneumonectomies if there is any contralateral lesion, and a further short segment is removed from the seventh rib allowing the scapula to fall in.

The chest is closed with a drainage tube in the eighth intercostal space after pneumonectomy, and in the second space anterolaterally after upper lobectomy, the pleura being closed with a continuous nylon suture. The intercostal bundles are approximated with interrupted thread sutures and tacked backwards to the erector spinae sheath. Where there has been an extrapleural dissection, the reconstructed chest wall may appear very ragged, but this has no adverse effect on the post-operative course. Antibiotics are only introduced intrapleurally if there has been soiling, reliance being placed on the routine systemic streptomycin and P.A.S.

A firm pad of wool is applied to the medial axillary wall and a second pad anterior to the pectoral muscles, retaining them with a many-tailed bandage. Pressure is maintained till about the tenth day, or till the chest wall is sufficiently firm to prevent paradoxical movement.

Postural drainage and controlled coughing are started the same evening by physiotherapists and carried out twice or more times daily till full aeration and free sputumraising are achieved. Post-operative aspiration of effusions is carried out 48 hours after operation and repeated if necessary.

The patient is allowed to sit out of bed after a week and after a further week he is allowed to go to the toilet. His subsequent time out of bed each day is increased depending on his temperature, the radiological appearances of the lung, and satisfactory bacteriological examination of the sputum. In general, the patient is kept in hospital till his sputum is negative for tubercle bacilli by culture and guinea-pig inoculation. $\mathrm{He}$ may then be discharged and is kept under constant supervision.

In the following tables details are given of pneumonectomies and upper lobectomies performed with concomitant thoracoplasty. To demonstrate satisfactory stabilization of the mediastinum, the position of the trachea relative to the midline or its pre-operative position has been measured. As a control, the position of the trachea after 27 pneumonectomies and 44 upper lobectomies carried out before the adoption of thoracoplasty was measured and these figures are quoted for comparison. It will be seen that resections plus thoracoplasty maintain a more satisfactory mediastinal position than those without.

TABLE I

Cases of Pneumonectomy plus Thoracoplasty

$\begin{array}{lllr}\text { Right side } & \ldots & \ldots & 8 \\ \text { Left side } & . & \ldots & 10\end{array}$

$\begin{array}{ccc}\begin{array}{c}\text { Ages } 18 \text { to } 30 \text { yrs. } \\ \text { Ages } 31 \text { to } 38 \text { yrs. }\end{array} & \ldots & 14 \\ \text { Total } & \ldots & \frac{4}{18}\end{array}$ 
TABLE I (contd.)

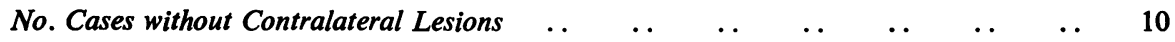

No. Cases with Contralateral Lesions

$\begin{array}{lllllllllll}\text { Stable over long period } & . & \ldots & \ldots & \ldots & \ldots & \ldots & \ldots & \ldots & 6\end{array}$

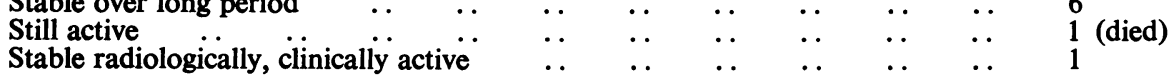

Sputum Analysis

$\begin{array}{lllllll}\text { Converted positive to negative (guinea-pig inoculation) } & \ldots & \ldots & \ldots & \ldots & 14\end{array}$

Remained negative

Remained positive and died

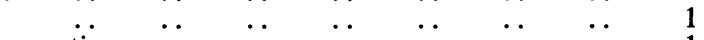

Complications

$\begin{array}{llllllll}\text { Bronchopleural fistula, empyema, death } & \ldots & \ldots & \ldots & \ldots & \ldots & \ldots & 1\end{array}$

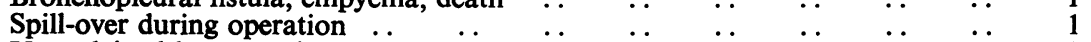

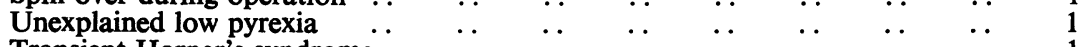

$\begin{array}{lllllllll}\text { Transient Horner's syndrome } & \ldots & \ldots & \ldots & \ldots & \ldots & \ldots & \ldots & 1\end{array}$

Position of Trachea Relative to Midline or Pre-operative Position

Thoracoplasty Series (18)

Unchanged or central

$7(39 \%)$

Deviated $\frac{1}{4}$ in. to operated side $6(33.3 \%)$

Deviated $\frac{1}{2}$ in. to operated side $4(22.2 \%)$

Control Series without Thoracoplasty (27)

Restored to midline 1

\section{Central}

$\frac{1}{4}$ in. to $\frac{3}{4}$ in

More than 1 in.

$2(7.4 \%)$

TABLE II

CASES OF UPPER LOBECTOMY PLUS THORACOPLASTY

Right upper lobes

Left upper lobes

Right upper lobe plus right middle lobe $\quad \ldots \quad$..

Right upper lobe plus apical lower segment $\quad \ldots$.

Left upper lobe plus apical lower segment ... ..

Left upper lobe plus wedge from basal segment $\begin{array}{lllllll}\ldots & \ldots & \ldots & \ldots & \ldots & 1\end{array}$

\begin{tabular}{llll} 
& Total .. &. & \\
\hline 20
\end{tabular}

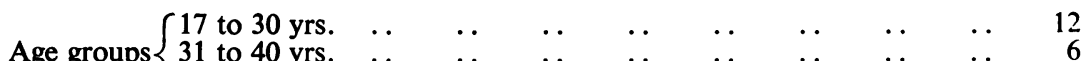

Age groups $\left\{\begin{array}{lllllllllr}31 \text { to } 40 \text { yrs. } & . & . & . & . & . . & \ldots & . & . & 6 \\ 41 \text { to } 49 \text { yrs. } & . & . & . & . . & . . & . & . & . & 6\end{array}\right.$

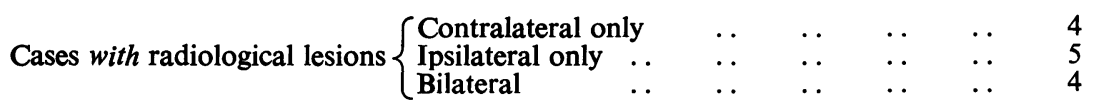

$\begin{array}{lll}\text { Total } \quad . . & \text {. } & \overline{13}\end{array}$

Reasons for Thoracoplasty in Cases without Residual Lesions

Small lung after right upper lobectomy

Right upper lobectomy plus apical lower .

Left upper lobectomy plus apical lower

Left upper lobectomy plus wedge of basals

Ages 36,39 , and 49 respectively

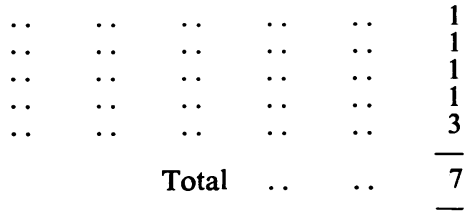

Sputum Analysis

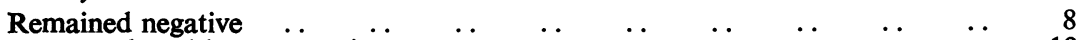

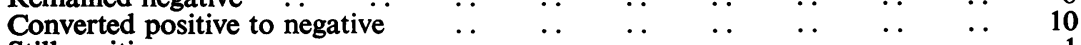

Still positive

Died 


\title{
Complications
}

\author{
TABLE II (contd.)
}

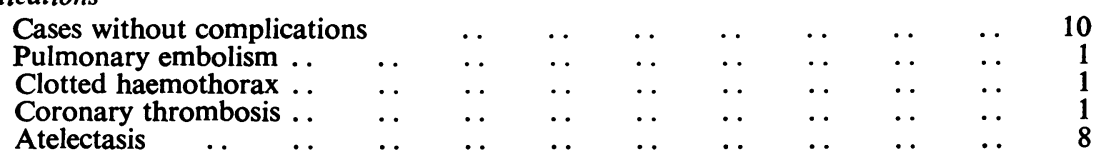

Position of Trachea Relative to Midline or Pre-operative Position

\begin{tabular}{|c|c|c|c|c|c|c|c|}
\hline \multirow{4}{*}{$\begin{array}{l}\text { Lobectomy plus } \\
\text { thoracoplasty } \\
\text { (20 cases) }\end{array}$} & \multirow{2}{*}{\multicolumn{4}{|c|}{$\begin{array}{l}\text { Unchanged } \ldots \\
\text { Deviated from pre-operative to operation side } \frac{1}{4} \ddot{\text { in. }} \text {. }\end{array}$}} & \multirow{3}{*}{$\begin{array}{l}\because \\
\therefore\end{array}$} & & \multirow{2}{*}{$\begin{array}{l}12(60 \%) \\
15(25 \%)\end{array}$} \\
\hline & & & & & & $\cdots$ & \\
\hline & Restored ,, & ", &, , midli & by $\frac{1}{4}$ in. & & . & $1(5 \%)$ \\
\hline & $\begin{array}{l}\text { Restored ,, } \\
\text { Died }\end{array}$ & ," & ," &,,$\frac{3}{4}$ in. & .. & .. & $(5 \%)$ \\
\hline obecto & Unchanged & . & & . & . & & $17(38 \%)$ \\
\hline thoracoplasty & Deviated by $\frac{1}{4} \mathrm{i}$ & o op & i side & .. & $\therefore$ & & $19(44 \%)$ \\
\hline (44 cases) & & & ," & .. & & . & \\
\hline
\end{tabular}

\section{COMPLications AND TREATMENT}

Pneumonectomy Cases.-One woman (M. H., aged 35) had a pneumonectomy performed for a destroyed right lung. It was known that she had an active lesion on the left side, but it was felt that coughing sputum from the bad side was maintaining activity on the opposite one and, though a bad risk, removal of the lung might give her a chance of survival. Her post-operative course was never satisfactory and she developed a bronchopleural fistula with a tuberculous empyema which led to her death.

A second woman (G. A., aged 29) had had an artificial pneumothorax for five years. It was decided to carry out a left pleuropneumonectomy, but it was difficult to clamp the bronchus early in the proceedings and secretion was spilt on to the opposite side, and the patient developed a small lesion in the upper zone three days post-operatively. The operation was performed in September, 1950, and the patient was treated for 12 weeks with streptomycin, P.A.S., and a continued pneumoperitoneum. She had a positive sputum six weeks post-operatively, but now, six months after the operation, the lesion has almost disappeared, she is symptomless, and negative to guinea-pig inoculation and culture.

A man (J. W., aged 28), who had a small calcified lesion at the right apex, had his left lung removed for widespread disease in July, 1950. Although the lesion shows no signs of reactivation he has an unexplained low-grade fever which has persisted. He feels well and his sputum is negative to all tests. He is still under observation.

The remaining 14 pneumonectomy cases were free from complications, had satisfactory post-operative courses, and are negative to guinea-pig inoculation and culture.

Upper Lobectomy Cases.-Of the 20 lobectomies, 10 were entirely free from complications post-operatively and subsequently. There was one death. A man (T.H., aged 26), who had a right upper and middle lobectomy in September, 1950, and developed a painless thrombophlebitis of his left leg, six days after resection had a pulmonary embolism and died immediately. Post-mortem examination of the pulmonary artery revealed a thrombus which exactly fitted the left saphenous vein from whence it had come. There was no warning that embolism was imminent and anticoagulant measures were not instituted.

One woman had a small clotted haemothorax which resolved spontaneously without trouble.

Coronary thrombosis occurred in a man (S.C., aged 49) from whom the right upper lobe and apical lower segment were removed for cavitating disease. He developed postoperative atelectasis of the middle lobe, which cleared with physiotherapy, but two weeks 
post-operatively he became dyspnoeic, and electrocardiography demonstrated a coronary thrombosis with right branch bundle block. This resolved with rest, and five months after resection he is quite well, free from cardiac or pulmonary symptoms, and has a negative sputum.

Including the above case, eight patients had varying degrees of ipsilateral atelectasis. Seven developed it two days after operation, but the eighth appeared when the phrenic nerve was crushed under local anaesthesia 10 days after resection. Intensive physiotherapy and postural drainage brought about resolution in four cases and full aeration was demonstrated clinically and radiologically within three days. The other four cases received courses of penicillin and sulphamezathine in addition to physiotherapy, and from two of these 1,000 and $1,400 \mathrm{c.cm}$. of air respectively were removed from the pneumoperitoneum. This resulted in the expectoration of plugs of viscid sputum and aeration of the lung. In no cases was there contralateral atelectasis and no cases were submitted to bronchoscopic aspiration.

The development of atelectasis appears to be related to the use of phrenic crush during the resection-thoracoplasty operation. This was suggested when it occurred in the patient whose phrenic nerve was crushed 10 days after resection. We tried to assess which patients were liable to develop atelectasis and, in these, deferred the phrenic crush till some days after resection or omitted it altogether. Table III analyses the cases in which atelectasis occurred, the suspected cause, and its relation to phrenic paralysis.

TABLE III

INCIDENCE OF ATELECTASIS

\begin{tabular}{|c|c|c|c|}
\hline Phrenic Crush & No. of Cases & Atelectasis & Suspected Cause \\
\hline $\begin{array}{l}\text { Performed some months } \\
\text { before operation }\end{array}$ & 2 & 1 & Bronchitic patient aged 37: uncooperative \\
\hline 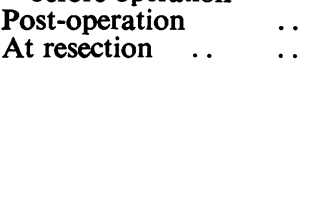 & $\begin{array}{l}3 \\
9\end{array}$ & $\begin{array}{l}1 \\
4\end{array}$ & $\begin{array}{l}\text { Fat, uncooperative, poor cougher } \\
\text { (1) Man, aged } 49 \text {, rigid thorax } \\
\text { (2) Woman, aged } 36 \text {, uncooperative } \\
\text { (3) Man, aged } 28 \text {; difficult operation; large } \\
\text { blood loss } \\
\text { (4) Woman, aged } 17 \text {; large pneumoperi- } \\
\text { toneum; very viscid sputum }\end{array}$ \\
\hline $\begin{array}{l}\text { Not done at all (by } \\
\text { choice) }\end{array}$ & 6 & 2 & $\begin{array}{l}\text { (1) Man, aged } 27 \text {; expected to be unco- } \\
\text { operative } 26 \text {; co-operative, but opera- } \\
\text { (2) Man, aged 20con } \\
\text { tion prolonged by decortication. }\end{array}$ \\
\hline
\end{tabular}

From this we conclude that young patients can have phrenic paralysis during resection, but if the operation is difficult or prolonged, and in the older patients, the nerve should be left intact and crushed later if the diaphragm is not high enough.

Up to date (March, 1951) no cases have developed subscapular space infections, none have radiological evidence of reactivation, and, with the exception of the pneumonectomy patient who died, none have developed bronchopleural fistulae and there have been no tuberculous or pyogenic empyemata.

\section{RESUlTS AND CONCLUSIONS}

Since the longest period over which these patients' progress has been followed is nine months and the shortest three months, the review can only be considered as an interim report. Of the pneumonectomy cases, eight had contralateral disease, and 
of the lobectomy cases 13 had residual lesions. No patient showed reactivation clinically or radiologically, though one with lobectomy still has a positive sputum. Serious complications were few, though atelectasis occurred in eight cases of lobectomy; this complication appears to be related to the use of phrenic crush during resection, and, though we believe that pneumoperitoneum should be used in practically all cases after resection, phrenic paralysis should only be carried out after consideration of the individual patient. There were two deaths in the series: one due to pulmonary embolism, the other to tuberculous empyema following a bronchopleural fistula which developed in a patient who was an extremely bad operative risk.

We believe that by protecting resections by thoracoplasty those cases with quiescent or doubtfully healed lesions can be undertaken safely and more patients can thus be accepted for resection. By performing thoracoplasty concomitantly with resection the patient is spared a second corrective operation, and the danger period in which the over-distension may occur is eliminated. The extra time taken for this procedure is rarely more than 20 minutes; shock is minimal ; and, up to now, only two patients have been considered unfit for it.

The modified thoracoplasty which we have adopted gives satisfactory control of the remaining lung and stabilization of the mediastinum and, at the same time, it is cosmetically satisfying to the patient and surgeon.

The true value of performing thoracoplasty concomitantly with resection can only be assessed on long-term results, and these should be compared with cases where no thoracoplasty has been done. In the meantime, we feel that the procedure is justified in those cases which fulfil the described indications.

I wish to thank Mr. Ronald Edwards for his advice, criticism, and encouragement in the preparation of this paper, and for the opportunity of performing some of the operations; also Mr. John Bickford, Dr. O. F. Thomas, and Dr. V. Cotton Cornwall for their individual help and interest.

\section{REFERENCES}

Brantigan, O. C., and Rigdon, H. L. (1950). J. thorac. Surg., 20, 109.

Burnett, W. E., Long, J. H., Norris, C., Rosemond, G. P., and Wester, M. R. (1949). Ibid., 18, 569.

Cournand, A., and Berry, F. B. (1942). Ann. Surg., 116, 532.

Himmelstein, A., Berry, F. B., and Read, C. T. (1950). J. thorac. Surg., 20, 866.

Iverson, R. K., and Skinner, H. L. (1950). Ibid., 19, 491.

Jones, J. C. and Robinson, J. L. (1950). Ibid., 20, 882.

Lester, C. W., Cournand, A., and Riley, R. L. (1942). Ibid., 11, 529.

Longacre, J. J., and Johansmann, R. (1940). Ibid., 10, 131.

Overholt, R. H., and Langer, L. (1949). The Technique of Pulmonary Resection, p. 169. Oxford.

Reinhoff, W. R. (1949). J. thorac. Surg., 18, 187.

Reichert, F. L., and Heuer, G. J. (1935). Bull. Johns Hopk. Hosp., 57, 373.

Sellors, T. H.(1950). Techniques in British Surgery, ed. Maingot, R., p. 179. Philadelphia and London.

Temple, L. J. (1951). Personal communication.

Thomas, C. Price (1950). Techniques in British Surgery, p. 206. 